\title{
Pedagogía, una disciplina indisciplinada: Límites de un debate y sus perspectivas ético políticas
}

\author{
Pedagogy: A Rebellious Discipline. \\ Boundaries of a Debate and Its Ethical- Political Perspectives
}

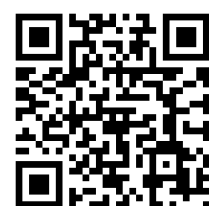

\author{
Juan Rafael Gómez-Torres ${ }^{1}$ \\ Universidad Nacional \\ Centro de Investigación y Docencia en Educación \\ Heredia, Costa Rica \\ correo: ggomezz1@gmail.com \\ orcid: http://orcid.org/0000-0001-5955-5869
}

Recibido 5 de octubre de 2015 • Corregido 24 de junio de 2016 • Aceptado 16 de agosto de 2016

Resumen. El presente estudio pretende realizar una ruptura con la matriz lineal clásica de la pedagogía, replanteándola así en interconexión de diferentes perspectivas o saberes de lo real, para ello propone a la pedagogía como una disciplina indisciplinada, que trasciende las fronteras segmentacioncitas y colonizadoras que se le adhieren. Se propone, pues, la indisciplina como una alternativa de resistencia, un acto de pensar-sentir-hacer otra pedagogía.

Palabras claves. Pedagogía indisciplinada, transdisciplinariedad, disciplinariedad, ruptura epistemológica, diversidad, ética y política.

Abstract. The present study aims to develop a rupture of the classical linear matrix about the concept of pedagogy. The proposal restates the idea of pedagogy within an interconnection of different perspectives and knowledge about reality as well. In order to reach that, the vision of pedagogy as a rebellious discipline is proposed. The colonialist and separatist boundaries that characterize pedagogy are discussed. Therefore, the concept of indiscipline as an alternative which resists the educational system is presented, and the new idea of pedagogy as an act of thinking-feeling-doing is analyzed.

Keywords. Unindisciplined pedagogy, transdisciplinarity, disciplinarity, epistemological rupture, diversity, ethics, and policy.

\footnotetext{
${ }^{1}$ Máster en Estudios Latinoamericanos con énfasis en Cultura y Desarrollo, Licenciado en Administración Educativa, Bachiller en Filosofía, en Enseñanza de la Filosofía, en Teología, en Enseñanza de la Religión y en Administración Educativa. Actualmente está en condición de Doctorando en la Carrera de Pensamiento Latinoamericano en el IDELA, UNA y es profesor e investigador en la División de Educología del Centro de Investigación y Docencia en Educación (CIDE) de la Universidad Nacional (UNA), Costa Rica.
} 
doi: http://dx.doi.org/10.15359/ree.20-3.25

URL: http://www.una.ac.cr/educare

CORREO: educare@una.cr

\section{Introduciendo lo intraducible: El problema de las disciplinas}

Mucho se ha discutido sobre la pedagogía como ciencia, en otros lugares se ha dicho que es ante todo una disciplina social y práctica para la vida y no solo para el trabajo (Gómez y Mora, 2011). En el presente escrito se sostiene que es una disciplina, pero "indisciplinada"; este tema roza con la idea de la "transdisciplinariedad", pues en última instancia la pedagogía trasciende el nicho disciplinar moderno del objeto de estudio abordado desde un centro gravitacional. Conjuntamente, se acepta que la propuesta en cuestión posee la limitación de nacer dentro de la academia, lugar que por su naturaleza tiende a estar dividido en disciplinas con poca o ninguna comunicación entre sí, lo que representa un reto mayúsculo para no caer en insondables contradicciones.

No obstante, el problema parece centrarse en el mismo origen donde surge este tema: las disciplinas y su tendencia a la división. Y, más que a la división, a la fragmentación. Como suele decirse en las ciencias naturales, así cuando tenemos claridad del objeto, el objeto ya está muerto. La división disciplinar, o bien, los intentos por revivirla mediante la multidisciplanariedad e incluso con la interdisciplinariedad, de poco sirven para restituir el conocimiento de los problemas sociales o humanos, sin que estos hayan muerto de hecho, a manos de las disciplinas, tal y como las conocemos hoy; o más bien, tal y como las hemos visto desarrollarse en los últimos siglos.

Siendo las humanidades y las ciencias sociales, ciencias o disciplinas, donde el objeto de estudio debe estar vivo y estarlo bien, es el lugar, donde el debate por una reconstrucción y en algunos casos, "deconstrucción" de las disciplinas, mediante un enfoque "indiciplinado" ha cobrado mayor fuerza e interés en los últimos años. Este enfoque pretende abordar un objeto de estudio desde múltiples saberes trabajando colaborativamente sin detenerse en la experticia, es decir, busca trascender las fronteras de las disciplinas.

En las siguientes anotaciones se pretende desarrollar la tesis subsecuente: precisamente la pedagogía es una aparente "disciplina", de entre las muchas que se divide el conocimiento moderno, la que, según nuestro criterio, no ha perdido su condición de complejidad ${ }^{2}$ y de cercanía con eso que hoy denominamos enfoque indisciplinado. No por accidente, sino por su propia naturaleza y amplitud hacia el conocimiento en general, lo que le ha permitido capearse los embates de la simple disciplinariedad, por ello se considera que la pedagogía es una forma compleja de construir conocimiento mediante objetos complejos. A diferencia de cualquier disciplina, la pedagogía, además de su aporte disciplinado que consiste en reflexionar sobre

\footnotetext{
${ }^{2}$ Entiéndase complejidad como una interrelación o interconexión propia de todos los seres, sistemas, ecosistemas y realidades entre sí. Proceso que es difícil de percibir y de analizar con herramientas y metodologías lineales y sin compromisos políticos, gnoseológicos, estéticos y éticos. Se entiende, pues, la complejidad como un campo de reflexión y de acción sin caer en visiones contemplativas, reduccionistas ni totalizantes, al menos eso se pretende desde una posición filosófica y pedagógica latinoamericana o de la liberación.
} 
la práctica educativa, reúne o requiere del aporte de otras disciplinas y saberes para realizar su tarea gnoseológica ${ }^{3}$ o dar posibles respuestas a los problemas educativos.

La fragmentación moderna de la ciencia en disciplinas ha tendido más bien a dividir los objetos, fragmentando la realidad, sin guiarse por sus propias condiciones y su forma de organización y sin recurrir para su explicación de la realidad al aporte cruzado de otras disciplinas involucradas en el fenómeno estudiado. En el caso de la pedagogía, su indisciplina radica en no seguir estrictamente la fragmentación disciplinar y acudir en su lugar a la ecología de saberes para cumplir, de mejor modo, su misión transformadora y con ello alcanzar la justicia cognitiva antecedente indispensable de la justicia social (Sousa, 2013).

Siguiendo a Freire (2005), ese carácter integrador de la pedagogía debemos politizarlo, dado su potencial transformador en pos de una mejor sociedad. Esto quiere decir que, en lo político, la pedagogía ha de enfatizar lo teleológico en el sentido de que la educación es ante todo para la vida, no para metas parciales o de corto tiempo. De allí que seguir la epistemología disciplinaria sería apegarse a su carácter colonizador, pues nos acerca a los procesos de dominación y sometimiento de la modernidad, al representar el saber de los grupos hegemónicos y su pretendida universalidad científica que invisibiliza los saberes o resistencias que se producen desde las víctimas de tal epistemología.

\section{Asesinando la diferencia: La disciplinariedad como oficio "patológico"}

Antes de centrarnos en el tema de la pedagogía indisciplinada como estrategia integradora, considero importante decir algunas palabras sobre el rastro colonizador de la disciplinariedad.

La ciencia moderna resultó mesiánica en el desierto oscuro del medievo europeo, ella vino a prometer progreso, objetividad, control de la naturaleza, resolución de enigmas, superación de la ignorancia o, en pocas palabras, la luz para iluminar y transformar a Europa en un "paraíso". Esa visión cartesiana y positivista llegó a Latinoamérica de modo impuesto y borrando todo rastro de mito y saber popular. Ese afán divino de la verdad clara y objetiva tuvo la fuerza de soportar embates desestabilizadores venidos de la misma Europa, como el presentado por el perspectivismo de Nietzsche, quien sostenía que cualquier representación del mundo corresponde a una interpretación realizada por un sujeto, por ello considera imposible el conocimiento dado el nivel de ilusión que posee este mismo. Es decir, considera la ciencia

\footnotetext{
${ }^{3}$ Me adhiero a la concepción de gnoseología entendida como un abordaje del conocimiento más allá de lo científico, en el caso de la pedagogía nos ayuda para alejarla de la obsesión por justificar su "carácter" cientificista. La gnoseología, en tanto teoría general del conocimiento, busca dar cuenta de los procesos de producción, reproducción, posibilidad, origen y estructuras del conocimiento humano. Lo que exige rigurosidad y empeño en la producción de la teoría educativa sin perder de vista su relación directa con la práctica.
} 
doi: http://dx.doi.org/10.15359/ree.20-3.25

URL: http://www.una.ac.cr/educare

CORREO: educare@una.cr

moderna como a una visión subjetiva que busca moderar la vida, apaciguando o deteniendo el candor de la voluntad de poder (Nietzsche, 2009).

Por su parte, la fenomenología con Husserl denuncia que "la ciencia ha dejado de lado el problema del sentido... de la vida" (Maldonado, 2011, p. 39) y propone la interpretación crítica de la realidad como método para producir mejores condiciones de vida. Otro embate a la ciencia moderna lo presentó la dialéctica marxista, para la que el conocimiento está en permanente contradicción, generando el movimiento hacia la transformación. A pesar de tal aporte, debido a su sesgo moderno, la dialéctica realiza síntesis de la realidad poniendo en peligro a la diferencia. Además de esas corrientes de la sospecha, existen otras que, aunque creyentes en la ciencia moderno occidental, cuestionan la posibilidad del conocimiento puro o del pretendido poder de omnipresencia de la ciencia.

Sin embargo, los pueblos latinoamericanos, seducidos por el saber europeo y norteamericano, han resistido de distintas formas el saber colonial, tal es el caso de los ensayistas anticoloniales e identitarios de principios del siglo XX, donde destacan Juan B. Alberdi, José Martí, José E. Rodó, Roberto Fernández Retamar, entre otros.

También destaca la resistencia propiciada por la pedagogía y la filosofía de la liberación que en los años cincuenta, sesenta y setentas del mismo siglo, muestran un camino propio, contextualizado y esperanzador para producir conocimiento o ciencia sin dejar de lado el saber popular ni al sujeto que lo produce, otrora negado por la ciencia europea impuesta en la región. Hoy destacan la pedagogía crítica, las pedagogías descolonizadoras, las pedagogías constructivistas y dialógicas, entre otras pedagogías que se indisciplinan ante el saber fragmentado, experto, unidimensional, colonial y al servicio de los grandes intereses económicos mundiales, regionales y nacionales.

Así, la pedagogía indisciplinada busca superar el asunto problemático de las disciplinas modernas como fragmentación de la realidad, ya la Escuela de Frankfurt había denunciado que los enfoques disciplinados se basan en la razón instrumental (Horkheimer, 1973), pues se componen de formalismos y metodologías endogámicas. Dicho de otra forma, su patología epistemológica no les permite la multidimensionalidad presente en la complejidad de lo real, sino que tiende a la unidimensionalidad y hegemonía totalizadora (Marcuse, 1993).

Para superar ese problema, en lo pedagógico se vuelve importante seguir la apuesta de corrientes epistemológicas, o más bien gnoseológicas, que hablan del pluralismo metodológico, como señala Antón (2004). Desde aquí se entiende "la ciencia como un modo de conocimiento, es decir, de relación con lo que nos rodea" (pp. 63-64) y fuera de la discusión sobre la verdad, por tanto, "no existe un modo cognitivamente privilegiado de considerar la entraña relacional de la realidad" (p. 65), lo que privilegia la distinción y permite "hablar de pluralismo sin desatar, necesariamente, luchas por la superioridad o la pureza teórica" (p. 65). 
Lo indisciplinado pasa por aceptar la complejidad de la realidad sin intentar atraparla en certezas ideológicas, pues como afirma Morin (1999), el "conocimiento es navegar en un océano de incertidumbres a través de archipiélagos de certezas" (p. 47). En ese sentido, se busca salir de una matriz lineal para pensar desde la interconexión de diferentes perspectivas o saberes de lo real, donde tiene lugar la incertidumbre, la irreversibilidad, la entropía, la disrupción, el no equilibrio, el caos y el (des)orden de modo espontáneo o natural, así como la justicia en la producción del saber.

$Y$ esto no parece posible desde un enfoque epistemológico patologizante como el disciplinarista, puesto que destruye la complejidad de la realidad (mediante un sinfín de disciplinas) para poder decir algo del mundo. Como en el viejo tópico de la rana en la clase de biología, a la cual, para conocer, es preciso "matarla" primero. Lo que sucede es que en el marco de las ciencias sociales y de las humanidades, la "muerte" de la realidad no se nos aparece inmediatamente, como en el caso de la rana de la clase de biología, aunque a la larga, tal cosa también suceda de manera inevitable y con efectos mucho más perversos sobre la vida.

\section{El carácter ético y político de la pedagogía como acercamiento indisciplinado para buscar el sentido de la vida}

Bien sabemos que la pedagogía, o al menos la mediación pedagógica, es ante todo un acto de amor que va más allá de lo disciplinar, pues al ser su "objeto" los procesos de enseñanza y aprendizaje, implica a las personas mismas. Entonces se hace imposible momificar al "objeto" para poder estudiarlo, es decir, son "objetos" que se deben tratar como sujetos. Ese acto de amor, que también implica el estudio de los saberes educativos para mejorar las prácticas docentes pasa por ser una actividad ética, dialógica, dialéctica y estética; en el decir de Freire (2005), es una acción-reflexión/reflexión-acción para enseñar y aprender a leer críticamente la realidad con el fin de transformarla y en el decir de Morin (1999), es un acto que por complejo debe ser holístico, multidimensional y planetario.

Ese cambio gnoseológico se hace imperioso para humanizar la mediación pedagógica y con ello enfrentar la escuela tradicional, fabricante de exclusión al reproducir la violencia estructural, el eficientismo del desempeño de los factores de producción, la mecanización, la burocratización pedagógica, la naturalización del esencialismo educativo, la eliminación de las diferencias, la legitimación de la desigualdad, la discriminación y el patriarcalismo. Siguiendo a Foucault (2000), en esa escuela tradicional, al no diferenciarse entre personas y productos, el estudiantado asume la forma del encierro.

Esa situación inhumana en lo académico y especialmente desde la docencia nos dice que ya no es suficiente con la reflexión científica verificacionista, se hace necesaria una pedagogía indisciplinada y desobediente de los mandatos del poder hegemónico, pues las ciencias y las humanidades deben encontrarse con otros saberes para buscar solución a las problemáticas 
doi: http://dx.doi.org/10.15359/ree.20-3.25

URL: http://www.una.ac.cr/educare

CORREO: educare@una.cr

educativas que nos rodean o nos interesa estudiar. Para abordar el problema desde varias perspectivas es preciso un nuevo desarrollo de capacidades, habilidades, destrezas y valores en los sujetos educativos.

Por otro lado, desde que se denunciaron las limitaciones del conocimiento humano (Kant) y desde que se globalizó de una forma abrumadora la información (sociedad del "conocimiento") se hace cada vez más difícil y estéril la producción del pensamiento desarraigado de la complejidad que le compete, y cada vez más es necesaria la generación de pensamiento crítico para seleccionar, de ese mar globalizado de información, lo que sea pertinente e imperioso para el contexto educativo al que se pertenece, fortaleciendo lo propio y desarrollando capacidades, habilidades, destrezas y valores críticos y comprometidos con el bienestar y la transformación social.

Si se entiende la pedagogía como un saber social o una socio-praxis capaz de unificar la producción y construcción del conocimiento educativo, dicho saber no puede ni debe reducirse a lo científico o lo metodológico, pues como se ha indicado, representa un compromiso con la vida misma, vida con acceso a la vivienda, alimentación, salud, servicios públicos como el agua, la electricidad y el teléfono, entre otros, y con el espacio para el crecimiento espiritual individual y social a través del trabajo, ocio, recreación, derechos humanos, autodeterminación, otros. Por eso, la pedagogía indisciplinada es un pensar-sentir-hacer desde y con el Otro u Otra ${ }^{4}$, constituyéndose en un acto horizontal, popular y democratizante.

Así vista, la pedagogía como socio-praxis supone reflexionar e investigar el quehacer educativo, pues como señala Bedoya (2005) la pedagogía no se reflexiona por sí misma; esto es, cuando el sujeto docente enseña, no necesariamente hace pedagogía, accede a la pedagogía como discurso, pero sin implicarse de forma consciente en el proceso y en las relaciones estructurales propias del saber pedagógico (Gómez y Mora, 2011). Por ello, surge la necesidad de un esfuerzo ético y político por ir más allá de lo que usualmente entendemos como pedagogía o como educación en un sentido más general. Así, la mediación pedagógica como acto de amor es una acción encaminada a facilitar el aprendizaje, entendido este como una dedicación para transformar nuestras vidas buscando el bienestar social y planetario.

Al ser la pedagogía indisciplinada una práctica reflexiva desde lo educativo y comprometida con la vida, el personal docente, para producirla, requiere de un acto intencionado, por lo que no es ni pretende ser neutral; como se denota, al profesorado le corresponde, por su propia situación, producir pedagogía, aunque no siempre lo hace. Si bien, las educadoras y los educadores son

\footnotetext{
${ }^{4}$ El Otro/Otra, se enfatiza con mayúscula pues la otredad es considerada como una exterioridad necesaria que da sentido a la vida, es el Yo soy si tú eres del que habla tanto Franz Hinkelammert. Es decir, no somos sin el Otro/ Otra, el Otro/Otra nos constituye como sujetos libres y autónomos pues solo en referencia a los Otros/Otras es que puedo saber quién soy, de donde vengo y para dónde voy. Sin el Otro/a solo soy sí mismo, mismidad o repetición, esto es, sin el Otro/Otra no hay identidad, pues identifico lo que soy ante su presencia y existencia.
} 
los Ilamados a producir pedagogía, esta a su vez debe trascender el claustro normalizador de la escuela para insertarse en todo el tejido social. Eso implica que, en el caminar indisciplinado de la pedagogía, todos y todas nos involucramos de algún modo en la tarea educativa, pues como señala Carr (1996, citado por Gómez y Mora, 2011, p. 19), el “no implicarse constituye una posición contraria a la misma práctica educativa, a la tarea de promoción de los aprendizajes propia de toda pedagogía, si comprendemos a éstas como una 'acción moralmente informada o moralmente comprometida"'.

Dicho de otra forma, el profesorado y todos los agentes pedagógicos no deben hacer caso omiso del principio de la vida plena o del responder a la satisfacción de las necesidades sociales: debe optar, éticamente, por quienes no han logrado un acceso a los beneficios económicos, culturales y sociales. Por tanto, la pedagogía es, ante todo, una práctica ética y política que tiene que ver con la formación integral de los seres humanos, buscando para ello encontrar las mejores formas de aprender y enseñar, de modo que se puedan comunicar distintas actitudes, saberes, valores, quehaceres, formas de hacer, de sentir, de estar y de ser. Pero nunca al margen de las necesidades sociales y de los requerimientos de quienes menos tienen y quienes son abandonados literalmente por la sociedad. O si no, ¿para qué educamos?, o mejor aún, ¿de quién es la educación?

Dicho con otras palabras, la pedagogía indisciplinada exige superar las visiones epistemológicas de la descripción, la predicción y el control que privilegian el binarismo reduccionista del sujeto y el objeto; pues, como señala Sousa (2009): "Todo el conocimiento es contextual pero el contexto es una construcción social, dinámica, producto de una historia que nada tiene que ver con el determinismo arbitrario de origen" (p. 360).

El problema no es fácil en el campo educativo, pues al trabajar la pedagogía con creencias, ideales, vivencias, prácticas, emociones, sentimientos propios del proceso de enseñanza y aprendizaje o, dicho de otra forma, al trabajar con la subjetividad que implica la formación humana, queda claro que el fin del conocimiento pedagógico será, ante todo, un conocimiento sobre la vida en general y no sobre alguna "parte" de ella, como sucede en el caso de los enfoques disciplinares.

\section{La pedagogía indisciplinada: Sus compromisos con la diversidad}

De lo señalado se extrae que la pedagogía como un área del saber social no debería homogenizar, invisibilizar, ni anular a nadie sino evidenciar su presencia y existencia a través del intercambio de saberes de manera integrada, ética y políticamente comprometida; dando, a la vez, gran valor a las diferencias o teniendo como centro gravitacional la diversidad. Se aprende en diversidad, somos diferentes; pero con el afán ético de alcanzar la igualdad social, igualdad imposible de alcanzar sin la lucha social permanente y sin las políticas públicas encaminadas hacia la equidad, el reconocimiento, la autodeterminación y la generación de oportunidades. 
doi: http://dx.doi.org/10.15359/ree.20-3.25

URL: http://www.una.ac.cr/educare

CORREO: educare@una.cr

Por eso, la analéctica ${ }^{5}$, corriente dialéctica latinoamericana, nos ha enseñado que para reconocer al Otro/Otra se debe reconocer el antagonismo como fuente de pluralidad; el conflicto no es polemización absurda sino diálogo respetuoso y generación de acuerdos mínimos a partir de las diferencias sin sintetizar al Otro/Otra.

En pocas palabras, nadie es, si se prohíbe que otros sean; o, como afirma Hinkelammert (2012), "yo soy si tú eres" (p. 171) o soy en "relación a [sic] los otros y a la naturaleza" (p. 205). Esa apuesta por la diversidad es un camino idóneo hacia la pedagogía del futuro, una pedagogía indisciplinada que busca un cambio cosmovisional, provocando cambios en el lenguaje y el pensamiento, orientados a reducir el pensamiento instrumentalista, patriarcal, dicotómico, simplista y civilizatorio (Adorno, 1998; Benjamin, 2010). Se dice cambios en el pensamiento y en el lenguaje, pues al igual que Vygotsky (1995) y Lenkersdorf (2005), en este escrito se considera que son inseparables y, por ende, la cosmovisión absorbe una ideología que está implícita en la estructura, por eso la importancia de ambos procesos en el aprendizaje y la cultura.

Aprender y enseñar son tareas diferentes y fundamentales de la pedagogía, donde aprender es un acto vital, un comprender a través de mediaciones para transformar la realidad. Cuando se aprende algo ya no somos más los mismos de antes, es decir, la educación puede hacer la diferencia entre la vida y la muerte. De allí la necesidad de una pedagogía de la vida y para la vida, que evite la totalización del Otro/Otra y propicie el encuentro, privilegiando la diferencia y evitando el consenso demoledor que nos impone la democracia liberal. Siguiendo a Benjamin (2010), la forma de salirse de ese usus normalizador es viendo lo normal (lo mismo) como un estado de excepción y lo extraño como el camino para alcanzar la diversidad, visibilizando la historia de las culturas anónimas (de los grupos vencidos, invisibles u olvidados: personas con discapacidades, indígenas, marginalizadas, de sexualidades diversas, mujeres, niños y niñas, migrantes, indigentes, entre otras).

Como consecuencia de una pedagogía comprometida con la vida, la diversidad es el extrañamiento de la otredad, o como creen los bribris de Costa Rica, todo tiene ser y todo ser tiene un lugar en el universo, todos los seres estamos en el universo para cumplir un propósito, ningún propósito es superior al del otro ser; pero tampoco es igual y esa diferencia debe cuidarse y mantenerse, esa diferencia es lo que permite el encuentro permanente de los seres desde su propio Kå (lugar y tiempo inseparables entre sí).

\footnotetext{
${ }^{5}$ Es un aporte que autores como Enrique Dussell adquieren un desarrollo profundo, evitando quedarse en la colonialidad del poder y del saber europeo, pues la dialéctica por más buenas intenciones está cargada de modernidad y como tal reduce el tema de la diferencia a la síntesis totalizadora. La analéctica es una metodología comunicativa o dialógica que pretende visibilizar la diferencia, dar el lugar que se le ha negado al Otro/Otra, no homogenizándole con la síntesis sino expresándolo desde su propia palabra y con esta, sin hacer cierres epistemológicos o consensos totalizadores. Así, en pedagogía interesa tanto la voz de las mayorías como las de las minorías y, sobre todo, las de los sectores minorizados.
} 
Así las cosas, una pedagogía indisciplinada o comprometida con la vida es aquella que:

- Parte del sujeto humano.

- Rompe con la linealidad y jerarquización de los procesos epistemológicos que privilegian al objeto sin contemplar la realidad del sujeto ni del contexto.

- Lacera la dualidad sujeto/objeto. Esta disolución epistemológica y ética es importante para poder llevar a cabo una pedagogía comprometida con la vida.

- Comprende que la construcción del conocimiento no es privilegio exclusivo de las personas expertas en pedagogía, sino que responde, ante todo, a los intereses, necesidades y expectativas de los sujetos sociales.

- Acepta la importancia de"especialistas"o profesionales en pedagogía, pero entendiendo que su aporte principal es el de facilitar procesos de aprendizaje de alta calidad crítica de manera integrada y transdisciplinar, partiendo de las necesidades, expectativas e intereses estudiantiles y de su comunidad educativa.

- Sabe que la producción del conocimiento implica una reconstrucción de saberes cotidianos a través de la acción de cada sujeto, implicando procesos de encuentro, recuperación, reinterpretación y negociación de sus bagajes culturales. Dichos procesos de recuperación y reconstrucción suponen, a su vez, procesos socioeducativos de enriquecimiento de la vida espiritual de las comunidades educativas.

- Rompe con las gestiones pedagógicas centradas en la técnica, la burocracia y el eficientismo, es decir, con lo "no social".

- Busca la ruptura de la cotidianidad institucional y, con ello, reorientar el sentido de "lo que se hace".

- Comprende la investigación como un proceso permanente de diálogo, donde no se privilegie a ningún sujeto en detrimento de otro, y donde los resultados respondan a procesos de consensos mínimos.

- Presenta a la investigación como un proceso pedagógico de aprendizaje colectivo, tendiente al mejoramiento de las condiciones de vida de todos los sujetos involucrados.

- Está dispuesta recuperarlos saberes populares para potenciar el cambio olatransformación de las condiciones de vida, poniéndolos al servicio de la comunidad educativa.

- Propicia la superación del naturalismo cognitivo mediante el aporte profesional docente, pero en un sentido ético donde se tiene presente que el aprendizaje tiene doble vía entre quien enseña y quien aprende. Esa desnaturalización de "verdades" 
doi: http://dx.doi.org/10.15359/ree.20-3.25

URL: http://www.una.ac.cr/educare

CORREO: educare@una.cr

incuestionables, ingenuas, heredadas e impuestas tiene el fin de fomentar el pensamiento crítico y transformador.

- Comprende que el cambio emerge, en primer lugar, de la producción del conocimiento, el mismo que provoca una transformación interna, pero también necesita de las posibilidades organizativas del actuar mediante el restablecimiento de los saberes populares.

- Favorece, en la práctica educativa cotidiana, nuevas formas de interacción pedagógica, estableciendo las relaciones existentes entre cada asignatura y las demás, de modo que se evite el segregacionismo temático o de asignaturas que sufre la escuela. Se podría pensar en talleres modulares de aprendizaje atravesados por problemas de interés personal y social, donde, para poder encontrar posibles soluciones, se necesite de un abordaje indisciplinado, planificado, ejecutado y evaluado con profundidad crítica.

\section{Conclusiones que no concluyen debido al carácter indisciplinado de la pedagogía}

Como primera conclusión, es necesario señalar que la indisciplina puede ser un camino importante para salir y resistir al disciplinarismo moderno que fragmenta y, con ello, dificulta la comprensión y transformación de la realidad, acercándonos indisciplinadamente a las formas de construcción del conocimiento de los pueblos y de las comunidades.

Además de esta "vía" indisciplinada, la pedagogía ha actuado dentro de la sociedad como articuladora de saberes, en sus más importantes facetas, es decir, en el marco de la producción de conocimiento por parte de los agentes educativos de la más diversa índole. En tanto que la misma parte de una concepción abierta y consecuente incluso con la Aufklärung ${ }^{6}$ europea, pero más que eso con la transdiciplinariedad del pensamiento decolonial latinoamericano, empezando sin duda con autores como Paulo Freire, Enrique Dussel, Moacir Gadotti, Katerine Walsh, Aníbal Quijano, entre otros?.

En la práctica educativa cotidiana se requiere de nuevas formas de interacción pedagógica no segregacionistas, se podría pensar en módulos de interés problemáticos que podrían o, hasta

\footnotetext{
${ }^{6}$ Iluminación o llustración alemana del S. XVII, la que buscaba entre otras cosas acercarse al análisis de la realidad mediante nuevas disciplinas, pues consideraba que las existentes eran insuficientes para dar cuenta de la realidad.

7 Estos autores son herederos legítimos de la tradición latinoamericana de las teorías de la liberación, en la actualidad luchan por consolidar un pensamiento emancipador basado en la descolonización, la anticolonialidad, la decolonialidad, la interculturalidad... del pensamiento, para con ello realizar una reelaboración del pensamiento propio, situado, localizado y contextualizado, que tome en cuenta y parta incluso de los saberes ancestrales (re) construyendo nuestra historia como camino hacia la transmodernidad. Según Dussel la transmodernidad incluye los aportes valiosos de la modernidad, pero adaptados a lo propios y desde allí busca superar la modernidad o el eurocentrismo epistemológico que impone el saber cientificista del norte como única ruta cultural posible.
} 
deberían, estar más allá de la segregación etaria para aprovechar la diversidad generacional a la hora de buscar alternativas inclusivas, rizomáticas y liberadoras, como propone el pensamiento complejo desde los de abajo, es decir, desde los pobres, oprimidos o minorizados ${ }^{8}$.

Por otro lado, tiempo, espacio, currículo, didáctica y evaluación parecen atentar contra la pedagogía de la vida y para la vida; pero, si se sigue un abordaje más amplio de la realidad, poco a poco se podrá llegar a una práctica educativa mucho más integral o cooperativa, lo cual no supone el abandono de la pedagogía aplicada a cada asignatura sino, sobre todo, el acercamiento desde diversas perspectivas para aprender y enseñar de mejor forma evitando pasar de un tema o asignatura a otra de forma segmentada e inconexa.

De esta manera, es necesario "concluir" que la pedagogía de la vida y para la vida, abordada desde la indisciplina, no solo abarca el marco de producción de conocimiento en sentido tradicional (es decir, por un grupo experto) sino que debe ser un ejercicio pedagógico amplio, donde la producción de sentido se entienda como parte de la actividad de todos los seres humanos, como construcción de conocimientos liberadores que permitan la construcción de un futuro viable para la humanidad.

\section{Referencias}

Adorno, T. W. (1998). Educación para la emancipación. Madrid: Morata.

Antón, I. J. (Enero-marzo, 2004). Pluralismo epistemológico: Entre el sueño objetivista y la inconmensurabilidad de paradigmas. Utopía y Praxis Latinoamericana, 9(24), 51-65. Recuperado de http://dialnet.unirioja.es/servlet/articulo?codigo=2692983

Bedoya, J. I. (2005). Epistemología y pedagogía: Ensayo histórico crítico sobre el objeto y métodos pedagógicos (6 $6^{\mathrm{a}}$ ed.). Bogotá: ECOE Ediciones.

Benjamin, W. (2010). Tesis sobre la historia y otros fragmentos (Ed. y Trad. B. Echeverría). Bogotá: Desde abajo. Recuperado de http://www.bolivare.unam.mx/traducciones/Sobre\%20 el\%20concepto\%20de\%20historia.pdf

Foucault, M. (2000). Vigilar y castigar: Nacimiento de la prisión. (24a ed.). México: Siglo XXI.

Freire, P. (2005). Pedagogía del oprimido. México: Siglo XXI.

\footnotetext{
${ }^{8}$ Entiéndase como aquela práctica política de negación o invisibilizaciòn de los grupos sociales que sin importar el número de personas que lo conformen se les considera minorías por el solo hecho de defender su diferencia constitutiva o por no seguir el estatus de la normalidad establecida para todas las personas. Enre esos grupos destacan los movimientos y personas LGTBIT, feministas, indígenas, personas con alguna discapacidad, pobres, mujeres, niñez, jóvenes, movimientos sociales, entre otros. Como se puede deducir, en algunos casos esos grupos son a veces mayorías, pero en todo caso minorizadas.
} 
doi: http://dx.doi.org/10.15359/ree.20-3.25

URL: http://www.una.ac.cr/educare

CORREO: educare@una.cr

Gómez, J. R. y Mora, M. A. (Julio-diciembre, 2011). Introducción: El largo caminar de la pedagogía. En J. R. Gómez y M. A. Mora (Eds.), Pedagogía del futuro. Educación, sociedad y alternativas (pp. 13-27). Ensayos Pedagógicos, edición especial.

Hinkelammert, F. (2012). Lo indispensable es inútil. Hacia una espiritualidad de la liberación. San José, Costa Rica: Arlekín.

Horkheimer, M. (1973). Crítica de la razón instrumental (2a ed.). Argentina: Sur.

Lenkersdorf, C. (2005). El mundo del nosotros. En E. Cohen y A. M. Martínez (Coords.), Lecciones de extranjería: Una mirada a la diferencia (pp. 147-153). México DF.: Siglo XXI.

Maldonado, C. E. (2011). Termodinámica y complejidad. Una introducción para las ciencias sociales y humanas. Bogotá: Desde Abajo. Recuperado de http://www.carlosmaldonado.org/ articulos/Termodinamica.pdf

Marcuse, H. (1993). El hombre unidimensional: Ensayo sobre la ideología de la sociedad industrial avanzada. Buenos Aires: Planeta-Agostini. Recuperado de https://foromemoriagranada. files.wordpress.com/2010/02/marcuse-h-el-hombre-unidimensional-1964.pdf

Morin, E. (1999). Los siete saberes necesarios para la educación del futuro. París: Unesco.

Nietzsche, F. W. (2009). La gaya ciencia. España: Akal.

Sousa, B. (2009). Una epistemología del sur. La reinvidicación del conocimiento y la emancipación social. México, D.F.: Clacso y Siglo XXI.

Sousa, B. (2013). La universidad popular del siglo XXI. Costa Rica: EUNA.

Vygotsky, L. S. (1995). Pensamiento y lenguaje. Teoría del desarrollo cultural de las funciones psíquicas. Ediciones Fausto. Recuperado de http://www.aacounselors.org.ar/adjuntos/ Biblioteca AAC/Lev S Vygotsky Pensamiento y Lenguaje.pdf

\section{Cómo citar este artículo en APA:}

Gómez-Torres, J. R. (Setiembre-diciembre, 2016). Pedagogía, una disciplina indisciplinada: Límites de un debate y sus perspectivas ético políticas. Revista Electrónica Educare, 20(3), 1-12. doi: http:// dx.doi.org/10.15359/ree.20-3.25

Nota: Para citar este artículo en otros sistemas puede consultar el hipervínculo "Como citar el artículo" en la barra derecha de nuestro sitio web: http://www.revistas.una.ac.cr/index.php/EDUCARE/index 